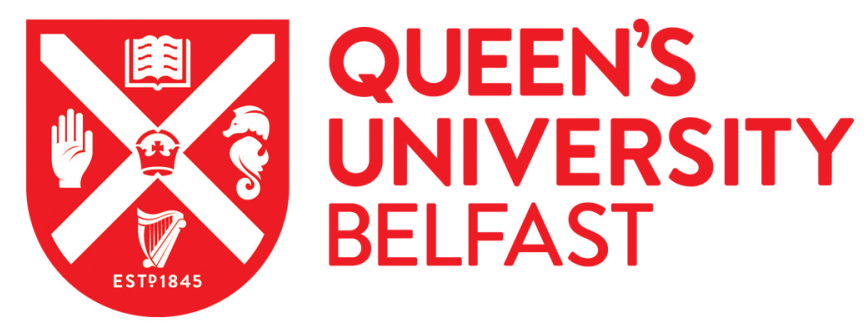

\title{
Translating the Women, Peace and Security Agenda into EU Common Security and Defence Policy: Reflections from EU Peacebuilding
}

Deiana, M-A., \& McDonagh, K. (2018). Translating the Women, Peace and Security Agenda into EU Common Security and Defence Policy: Reflections from EU Peacebuilding. Global Society, 32(4), 415-435. https://doi.org/10.1080/13600826.2018.1474183

\section{Published in:}

Global Society

\section{Document Version:}

Peer reviewed version

Queen's University Belfast - Research Portal:

Link to publication record in Queen's University Belfast Research Portal

\section{Publisher rights}

(c) 2018 University of Kent.

This work is made available online in accordance with the publisher's policies. Please refer to any applicable terms of use of the publisher.

\section{General rights}

Copyright for the publications made accessible via the Queen's University Belfast Research Portal is retained by the author(s) and / or other copyright owners and it is a condition of accessing these publications that users recognise and abide by the legal requirements associated with these rights.

Take down policy

The Research Portal is Queen's institutional repository that provides access to Queen's research output. Every effort has been made to ensure that content in the Research Portal does not infringe any person's rights, or applicable UK laws. If you discover content in the Research Portal that you believe breaches copyright or violates any law, please contact openaccess@qub.ac.uk. 
Title: Translating Women, Peace and Security (WPS) Agenda into EU Common Security and Defence Policy (CSDP): Reflections from EU peacebuilding.

\author{
Maria-Adriana Deiana, m.deiana@qub.ac.uk, Queen's University Belfast and \\ Kenneth McDonagh, kenneth.medonagh@dcu.ie, Dublin City University
}

Accepted manuscript Global Society, 32:4, 415-435, DOI:

$10.1080 / 13600826.2018 .1474183$

\begin{abstract}
Existing studies of European Union Common Security and Defence Policy ( EU CSDP $)^{1}$ missions often rely on a conceptualisation of Women, Peace and Security (WPS) implementation as a technical, linear and deterministic process. While this scholarship is part of a concerted effort to develop an accountability mechanism and push for organizational change, this paper contends that we also need a more grounded and contextual approach to capture the complex, ambivalent and often tortuous translation of WPS into CSDP relatively new security practices. This suggests that a deeper interrogation of what meaning(s) mainstreaming gender assumes in the context of EU CSDP missions and how this conceptualisation informs the practice of peacekeeping is required. Drawing on interviews with EU peacekeeping personnel we outline an ambivalent account of how different CSDP actors interpret WPS and gender mainstreaming and compose it in use, with different effects.
\end{abstract}

Keywords: gender, peace, security, practice turn, EU normative power

\title{
Introduction
}

This paper addresses the developing field of research that tracks the articulation and translation of the Women, Peace and Security (WPS) Agenda in the complex institutional and operational contexts of international peacekeeping. More specifically it engages with emerging research that explores the EU's role in the promotion global gender norms in the context of

\footnotetext{
${ }^{1}$ The Common Security and Defence Policy of the European Union evolved from a Franco-British Summit in St Malo in 1998. It has led to a series of initiatives aimed at developing the EU's capacity in the areas of security and defence. including peacekeeping and peacebuilding missions, defence procurement, and joint training and operations. For an overview of CSDP see Mark, Mark, Stuart Croft, Jolyon Howorth, Terry Terriff, and Elke Krahmann. (2004). 'The governance of European Security' Review of International Studies 30 , no. 1, 3-26,.doi: 10.1017/S0260210504005807; and Maria Mälksoo. "From the ESS to the EU Global Strategy: external policy, internal purpose." Contemporary Security Policy 37 no 3 (2016): 374-388 10.1080/13523260.2016.1238245
} 
security $^{2}$. The findings discussed here are part of a larger project that examines the ways in which WPS commitments are mainstreamed, operationalised and negotiated in all stages of EU peacekeeping missions, from the planning stages in the Crisis Management and Planning Directorate in Brussels to deployment and operationalisation in the field. Our contribution draws upon the innovative potential of the recent "practice turn" in International Relations (IR) and critical security studies to explore the incorporation and operationalisation of Women, Peace and Security policy objectives in the practice of peacekeeping with a focus on the civilian mission EULEX in Kosovo, our main case-study for the paper. We draw on a combination of in-depth interviews and informal conversations with EULEX personnel, including the international gender advisor, gender focal points and another non-gender-specialist member of staff. The paper is also informed by interviews and informal conversations we conducted with mission planners in Brussels and gender advisors working in deployed CSDP missions and the External European Action Service.

Our fieldwork focused on how WPS has been implemented in the field and how EU policy commitments have been translated in deployments such as EULEX. Drawing on existing research on feminist institutionalism, we were concerned with identifying key strategies, actors and partnerships supporting implementation, or the lack of thereof. Although we briefly analyse high level policy documents such as the 2008 EU Council decision on implementing UNSC1325 on WPS $^{3}$, the lack of access to operational level documentation meant that such an analysis sheds limited light on how WPS is translated in the field. As Muehlenhoff notes "That gender equality is included in EU foreign policies is a success but it's ambiguous foundations need to be discussed and investigated more." ${ }^{4}$ Operational peacekeeping documents are frequently classified and gaining access is often an unpredictable and difficult process, therefore conducting interviews with key personnel was chosen as the most appropriate means to engage in this investigation. These research encounters yield a rich

\footnotetext{
${ }^{2}$ Roberta Guerrina and Katarine Wright, 'Gendering Normative Power Europe', International Affairs, Vol.92, No.2 (2016)pp.296-312 ; Paul Kirby and Laura J. Shepherd, 'The Futures Past of the Women, Peace and Security Agenda', International Affairs 92, no. 2 (2016): 373-392; Louise Olsson and Karin Sundström, 'European Union's Gender Policy for CSDP Missions: Contents and Gaps'(2013) accessed 3 October 2016, https://fba.se/contentassets/8ed4b9c1a27c4c1dbc20d51172d6e83e/policy-review_eu-gender-policy-forcsdp.pdf; Maria Stern, 'Gender and Race in the European Security Strategy: Europe as a "force for Good"?', Journal of International Relations and Development 14, no. 1 (2011): 28-59, doi:10.1057/jird.2010.7.

${ }^{3}$ Council of the European Union. (2008). Comprehensive approach to the EU implementation of the united nations security council resolutions 1325 and 1820 on women, peace and security.; available at: http://www.seesac.org/f/img/File/Res/Gender-and-Security-Resources/EU-implementaion-of-the-UNSCresolutions-Women-639.pdf accessed 15/01/2018

${ }^{4}$ Hanna L Muehlenhoff (2017) "Victims, soldiers, peacemakers and caretakers: the neo-liberal constitution of women in the EU's security policy” International Feminist Journal of Politics 19 no. 2, p.164
} 
and complex picture of the interpretations and decisions underpinning the practice of WPS implementation, gesturing to the need to develop a thicker understanding of the actors and conditions shaping the process.

We begin by situating our analytical framework of WPS as practice within current feminist scholarship that traces WPS travelling within EU CSDP. This scholarship in turn builds on the extensive work on UNSC1325 and its implementation both in policy, in the form of National Action Plans and in practice. ${ }^{5}$ A key finding of this literature is that policy initiatives in the area of WPS from the global to the local, tend to translate gender in problematic ways that either perpetuate problematic themes of women as passive victims or where agency is acknowledged fail to address the broader structural issues that limit women's capacity to act. ${ }^{6} \mathrm{We}$ suggest that a turn to practice offers a fruitful approach to develop a more contextual analysis and "populate" the implementation process with the perspectives of actors involved in order to gain a more subtle understanding of how WPS operates in practice. ${ }^{7} \mathrm{We}$ then introduce the policy context shaping WPS at the EU level, outline the mandate and operation of EULEX Kosovo and the gender mainstreaming mechanism developed in the mission. In the final part, we draw on personal interviews to explore the operationalisation and negotiation of gender mainstreaming commitments underpinning the practice of peacekeeping. Interviews offer a productive entryway to zoom into the micropolitics of the mission and gain a contextual understanding of the (f)actors shaping the articulation of WPS. We draw attention to the juncture between the conditions shaping the creation of a gender mainstreaming mechanism, the role of gender advisors as policy translators and negotiators, the proliferation of gender focal points as "new" WPS actors, and the contextual complexity of the mission as an international microcosm. The paper ends with a methodological reflection on undertaking a practice-based research.

\section{Moving beyond institutions and policy: WPS a practice}

\footnotetext{
${ }^{5}$ See for example Nicole George and Laura J. Shepherd, Eds. (2016) "Special Issue: Women, peace and security: In Regional, National and Local Contexts" International Political Science Review Vol 37 No 3 pp.297-403 ${ }^{6}$ See Annika Bjorkdahl and Johanna Mannergren Selimovic (2015) 'Translating UNSCR 1325 from the global to the national: protection, representation and participation in the National Action Plans of Bosnia-Herzegovina and Rwanda' Conflict, Security and Development, 15 no.4, pp.311-335;; and Hanna L. Muehlenhoff (2017) Victims, soldiers, peacemakers and caretakers: the neoliberal constitution of women in the EU's security policy, International Feminist Journal of Politics, 19 No 2, 153-167

${ }^{7}$ For a bottom-up insight to how the WPS agenda is implemented in Balkan context see Laura McLeod (2011) 'Configurations of Post-Conflict: Impacts of Representations of Conflict and Post-Conflict upon the (Political) Translations of Gender Security within UNSCR 1325' International Feminist Journal of Politics 13 No.4, pp. 594-611
} 
Over the past ten years, the European Union has been clear in its commitment to gender mainstreaming in its external relations, including peacekeeping and crisis management. On paper, at least, the organisation has adopted a comprehensive WPS agenda. However, when examined by researchers, this policy commitment falls short in practice particularly in the area of Common Security and Defence Policy. ${ }^{8}$ Both within the EU External Action Service (EEAS) and in the EU's deployed missions, critics find that the transformative potential of introducing a gender perspective has been under-exploited due to the gap between declared policy commitments and the real institutional supports available to translate these into action. ${ }^{9}$ Within this scholarship, there is some disagreement as to why the EU fails to live up to its commitments and varying levels of optimism about the potential for the still nascent EU CSDP and broader external relations to improve. These reflect a broader interplay between integrationist approaches that aim to better incorporate gender policies within the current EU system -on the grounds that this will eventually lead to cultural and institutional change- and more critical perspectives- that also raise larger questions about the ideological underpinnings of the EU, its attendant conceptualisation of gender and security.

For example, Olsson et. al.'s case study analysis of current CSDP missions points out that shortcomings in the systematic mainstreaming of gender derive from a lack of strategic planning and of robust institutional support in the field. ${ }^{10}$ To bridge this gap they suggest a practical assessment framework with a strategic focus and a clearer set of guidelines to more effectively translate the goals of WPS into CSDP mission outcomes. From a feminist institutionalist perspective, Roberta Guerrina and Katharine Wright argue that the lack of feminist actors in strategic positions and feminist networks focussed on influencing the EEAS and CSDP, as occurred in other EU policy areas, limits the implementation of the WPS agenda. ${ }^{11}$ This lack of feminist actors and networks means that the problem of effectively

\footnotetext{
${ }^{8}$ Guerrina and Wright, 'Gendering Normative Power Europe'; Louise Olsson et al., 'Gender, Peace and Security in the European Union's Field Missions', https://fba.se/contentassets/bcfe134c7ace454c964c1cf68f856474/fba_csdp_rapports5_web_141217.pdf.

${ }^{9}$ Helena Carreiras, 'Women and Peace Operations', in Managing Crises, Making Peace (Springer, 2015), 69-90, http://link.springer.com/chapter/10.1057/9781137442253_4; Olsson et al., 'Gender, Peace and Security in the European Union's Field Missions'; Karen Barnes, 'Briefing Note: On Gender, Peace, Security and Development; What Can the EU Do?', 2011, https:/epthinktank.eu/2014/02/11/women-peace-and-security/.

${ }^{10}$ Olsson et al., 'Gender, Peace and Security in the European Union's Field Missions'.

${ }^{11}$ Roberta Guerrina and Katharine AM Wright, 'Gendering Normative Power Europe: Lessons of the Women, Peace and Security Agenda. Developed by Alison Woodward, the term velvet triangles encapsulates constellations of key actors that explain the emergence and development of gender policy within the EU, see also Alison, Woodward, 'Building velvet triangles: gender and informal governance', in Thomas Christiansen and Simona Piattoni ,eds, Informal Governance and the European Union (Cheltenham: Edward Elgar, 2003), pp.7693
} 
translating WPS into action in EU missions is rooted not in imperfect implantation or diffusion but rather in the uncritical and unchallenged assumptions about the gender neutrality of security issues that is embedded in European security policy institutions. Constructed in this way, gender can only be an extra or afterthought to missions rather than incorporated as a necessary condition of progress in conflict resolution and post-conflict reconstruction.

Therefore, although this paper shares a focus on the ways in which WPS commitments are mainstreamed, operationalised and negotiated into CSDP policy and practice and in tracking the micropolitics of this process with Olsson et al., we wish to challenge the way gender mainstreaming is constructed as a somewhat linear and determinist process. We argue that in order to deliver on the transformative potential of WPS we must move beyond the focus on development of specific goals, assessment methods and indicators we see repeated in the various systems of indicators that constitute the machinery for the implementation of UNSCR1325 \& sister resolutions developed by EU and UN. While some might view the development of such goals and indicators as part a concerted effort to create accountability and keep track of WPS implementation, these numeric measures are contested for being overly reductive and not useful for capturing contextual complexity. Furthermore, we wish to scrutinise an implicit assumption of this approach: that there is a determined meaning attached to WPS and gender mainstreaming, that all actors share that meaning and will act accordingly to pursue predetermined identifiable goals.

In order to unearth the consequences of this assumption, this paper attempts to draw together elements of the existing empirically-driven literature on WPS implementation, and the recent practice-turn in IR and critical security studies. ${ }^{12}$ Although there are a variety of approaches to the practice turn in IR, we take as a starting point the importance of the study of 'micropractices and everyday world politics, both of which play a role in bringing about changes in broader security...dynamics' ${ }^{13}$ By focusing on WPS as a form of knowledge moving through the practices of mission participants we can trace the learning and socialisation effects of

\footnotetext{
12 Katharine AM Wright, 'NATO'S Adoption of UNSCR 1325 on Women, Peace and Security: Making the Agenda a Reality', International Political Science Review 37, no. 3 (1 June 2016): 350-61, https://doi.org/10.1177/0192512116638763; Joanna Valenius, 'Gender Mainstreaming in ESDP Missions', 2007, http://www.iss.europa.eu/publications/detail/article/gender-mainstreaming-in-esdp-missions/; Rebecca AdlerNissen, 'Towards a Practice Turn in EU Studies: The Everyday of European Integration', JCMS: Journal of Common Market Studies 54, no. 1 (1 January 2016): 87-103, https://doi.org/10.1111/jcms.12329; Karine CôtéBoucher et al., 'Border Security as Practice: An Agenda for Research', Security Dialogue 45, no. 3 (1 June 2014): 195-208, https://doi.org/10.1177/0967010614533243; Didier Bigo, 'The (in)Securitization Practices of the Three Universes of EU Border Control: Military/Navy - Border Guards/Police - Database Analysts', Security Dialogue 45, no. 3 (1 June 2014): 209-25, https://doi.org/10.1177/0967010614530459.

${ }^{13}$ Emanuel Adler and Vincent Pouliot (2011) 'International Practices' International Theory 3 No. 2, P.28
} 
Gender Advisors and similar roles. In this sense, we assume that communities of practice represent sites where both continuity and change processes may occur. ${ }^{14}$ This allows us to develop a focus on a thicker contextualisation of WPS as practice, that is, relationally constituted in the production, re-production and contestation of the various meanings WPS assumes in the institutional space of EU CSDP. This approach enables a deeper interrogation of how, and to what effect, a range of EU actors mobilise WPS discourses when they speak, mainstream and operationalise gender in peacekeeping. Interviews are used as means of accessing these narratives. As Adler-Nissen notes 'Interviews are important, not because informants know the 'big-T' truth, but because their particular truths are valuable.' ${ }^{15}$ By zooming into the personal narratives we can unearth and foreground how individual interpretations. representations and contestations influence how rhetorical policy commitments translate into specific security practices. ${ }^{16}$ Following Wibben, we view narratives as primary sites where meaning is produced, intentions are articulated and legitimacy is constructed that are crucial for a deeper understanding of WPS' journey into CSDP. ${ }^{17}$ Focusing on the "view from below" that a practice approach affords us, we gain a more nuanced picture of the dynamics shaping the reproduction, alteration and transformation of security practices in CSDP missions. Tracing the ways in which WPS concerns might enter in the shared repertoire of CSDP practices, we capture a complexity and ambiguity that might be overlooked in accounts that focus on the strategic and institutional level of implementation. Our aim is to complement existing studies of WPS implementation in the context of CSDP by bringing to the forefront everyday agents and the conditions that make WPS travelling into CSDP routinized practices possible.

From policy commitments to EU peacekeeping mandates: the framing of WPS in EU CSDP.

The context for the EU's increased importance as an actor in the area of gender, peace and security is its emergence as a global security organisation over the past 20 years and the deployment of EU missions abroad. Its record within the member states in delivering on gender equality also holds much promise if it manages to effectively translate these standards into external action. The policy framework for the implementation of WPS in CSDP is set out in

\footnotetext{
${ }^{14}$ Nina Graeger (2017) 'Grasping the everyday and extraordinary in EU-NATO relations: the added value of practice approaches’ European Security 26 no.3 , p.350

${ }^{15}$ Rebecca Adler-Nissen 'Towards a practice turn' p.97

${ }^{16}$ We found Sam Cook's piece particularly useful in thinking through the relationship between WPS meanings, narratives and practices Sam Cook, "The "Woman-in-Conflict" at the UN Security Council: A Subject of Practice', International Affairs 92, no. 2 (1 March 2016): 353-72, https://doi.org/10.1111/1468-2346.12553.

${ }^{17}$ Annick TR Wibben, Feminist Security Studies: A Narrative Approach (Routledge, 2010), 2.
} 
two key documents. The first is the Comprehensive Approach on EU Implementation of the United Nations Security Council Resolution 1325 and 1820 On Women, Peace and Security. This document sets out the basic principles the EU uses to approach gender mainstreaming in crisis management. ${ }^{18}$ It envisions multi-sited interventions across divers policy areas, from state building to gender based violence to women's participation and recommends the creation of indicators for monitoring implementation. ${ }^{19}$ In response to the Comprehensive Approach and to the creation of a monitoring system at the UN level, the EU has subsequently developed a list of 15 indicators adopted in 2010 and subjected to a process of continued revisions which yielded the first report in 2011. ${ }^{20}$ The second key document is the Lessons And Best Practices of Mainstreaming Human Rights and Gender Into CSDP Military Operations And Civilian Missions which outlines more specifically the ways in which the EU operationalises mainstreaming gender within different stages of CSDP missions in response to evidence gathered from "the daily work of CSDP operations and missions". ${ }^{21}$ As discussed above, while the development of such strategies aimed at measuring the effectiveness of implementation is seen as a necessary step in unleashing WPS transformative potential, our research suggests that such an approach does not sufficiently account for the complexity of interactions that might lead to, or prevent, qualitative change .

Examining the mapping of WPS into the context of EU external action policy, we find that the tensions identified by feminist scholars examining the implementation of the agenda

\footnotetext{
${ }^{18}$ Council of Europe, 'Council of Europe, 2008, Comprehensive Approach on EU Implementation of the United Nations Security Council Resolution 1325 and 1820 on Women, Peace and Security', 2008, http://www.consilium.europa.eu/ueDocs/cms_Data/docs/hr/news187.pdf. accessed 9 May 2016

${ }^{19}$ Carreiras, op.cit.

${ }^{20}$ The fifteen anniversary of UNSCR1325 in 2015 sparked a renewed momentum in the international arena for gender, peace and security policies. In this context, a series of policy documents sought to reaffirm EU commitment to foreground gender and human rights in the context of development, democracy and more broadly in its external relations, see: European Commission, 2015 Gender Equality and Women's Empowerment : Transforming the Lives of Girls and Women through EU External Relations 2016-2020, available https://ec.europa.eu/europeaid/joint-staff-working-document-gender-equality-and-womens-empowermenttransforming-lives-girls-and_en (accessed 9 May 2016). More specifically in July 2015 the Council presented a new Action Plan on Human Rights and Democracy for 2015-2019 that, among its proposals, includes a chapter on "Mainstreaming Human rights into all phases of CSDP planning, review and conduct". In the same month, the Council Conclusions also requested a baseline study on the incorporation of WPS into all aspects of CSDP, which at the time of writing is yet to be published. The overall rationale for the new action plan and the baseline study is an effort to improve strategic implementation at all CSDP levels, reporting, and coordination among Member States, EEAS and other relevant institutions such as the Commission or the Council. As these are recent developments at the time of writing, it is difficult to assess the full implications and impact of these new strategies. ${ }^{21}$ Council of Europe, 'Lessons and Best Practices of Mainstreaming Human Rights and Gender into CSDP Military Operations and Civilian Missions', https://www.civcap.info/fileadmin/user_upload/Working_Group/CIVCOM_LessonsLearned.pdf.
} 
in the architecture of international security recur here. ${ }^{22}$ Our research confirms the failure of the EU to realise the transformative potential of UNSCR1325 and further, that the manner of implementation has served to depoliticise and render operationally irrelevant the feminist insights and aspirations that were at the heart of the movement to create the WPS agenda in the first place. ${ }^{23}$ Instead of transforming the practice of missions through gender lenses we find the implementation of WPS by the EU to be focussed on a narrowly defined range of targets focussed on gender balancing mission staffing and only addressing gender in the very specific context of gender-based violence in conflict. ${ }^{24}$ One effect of this narrow framing is the manner in which gender mainstreaming policies are often framed in relation to conflict sites out there over the EU external frontier and understood by CSDP as concerned with "others", be it the host population, old-fashioned colleagues or female colleagues. ${ }^{25}$ Our interviews with mission planners were particularly insightful in highlighting a certain resistance to engage reflexively with questions of gender inequality. Rather questions of security and crisis management were framed as gender-neutral with the 'value' of WPS framed in terms of its impact on operations rather than on deeper questions of gender relations.

A key question for our study was examining this framing of WPS moving into the deployment stage, how did it translate into the evolving CSDP missions' mandate and operations. EULEX represents an ideal case in this regard, its extensive mandate allowed us to explore the incorporation of gender concerns in the practices of crisis management, peacekeeping, as well as post-conflict transition. Deployed in December 2008, EULEX assumed responsibilities in the areas of police, customs and the judiciary in Kosovo. It has been the largest CSDP mission to date, EULEX has employed 1,950 international and 1,250 local staff. ${ }^{26}$ The EULEX mandate focused on three objectives: ensuring the maintenance of security and rule of law, to include the contested context of the North; addressing politicised crimes, such as war-crimes, inter-ethnic tensions and corruption; and favouring the long-term integration of the region within the EU through support for the Belgrade-Prishtina dialogue.

\footnotetext{
${ }^{22}$ Maria-Adriana Deiana and Kenneth McDonagh, “"It Is Important, But...”: Translating the Women Peace and Security (WPS) Agenda into the Planning of EU Peacekeeping Missions', Peacebuilding, 2017, 1-15.

${ }^{23}$ For a concise review of these tensions see for example Cook, 'The "Woman-in-Conflict" at the UN Security Council'.

${ }^{24}$ Sara Meger, 'The Fetishization of Sexual Violence in International Security', International Studies Quarterly 60, no. 1 (2016): 149-159.

${ }^{25}$ Deiana and McDonagh,op.cit.

${ }^{26}$ Gezim Visoka and Grace Bolton, 'The Complex Nature and Implications of International Engagement after Kosovo's Independence', Civil Wars 13, no. 2 (1 June 2011): 189-214, https://doi.org/10.1080/13698249.2011.576158; Andrew Radin, 'Analysis of Current Events:"Towards the Rule of Law in Kosovo: EULEX Should Go”', Nationalities Papers 42, no. 2 (2014): 181-194.
} 
EULEX has pursued its mandate by performing both "strengthening" and "executive" functions. The strengthening function was envisioned to improve the quality of Kosovo's rule of law institutions through the strategy of Monitoring Mentoring and Advising. The executive functions involved EULEX officials directly securing the rule of law through investigations, public security efforts, and judicial affairs. It has been noted that "strengthening" functions emerged publicly as the core objective of the mission. ${ }^{27}$ On the other hand, EULEX has tended to de-emphasise its executive role in order to maintain its neutrality on Kosovo's independence, minimise its perceived imposition on the local politics and as a result of its highly bureaucratic working culture ${ }^{28}$ Its activities have been shaped by long-standing tensions in the North revolving around the dismantling of the existing Serb parallel structures, the devolving of powers to local institutions, as well as investigations on allegations of its misconduct. As a result of the transitionary nature of the mission and because of investigations on its operation, EULEX's mandate and operational capacity have been continuously revised and progressively downsized. At the time of writing the mission has approximately 730 international staff and 750 local staff and its mandate runs until June 2018.

As one of the first EU mission with an extensive mandate ranging from the rule of law, to human rights and the judiciary, EULEX presents an interesting case study for exploring the application of Women, Peace and Security agenda given that these objectives and their inherent gender dimension figure prominently within EU policy commitments. Another aspect determining our case study selection lies in that the mission has demonstrated an explicit commitment to strengthening its gender mainstreaming mechanism in cooperation with the Folke Bernadotte Academy (FKA), a Swedish government agency connected to the Ministry of Foreign Affairs. This cooperation which led to the development of a gender focal points system and a number of gender specific trainings designed by FBA could be seen as an indication of best practice in the context of EU peacekeeping. Since training and informal socialisation practices are critical for establishing a community of practice through the creation of a shared repertoire of competent performances, we were interested in exploring whether opportunities for change were enabled by this process. While our fieldwork at EULEX illustrates important efforts in translating WPS into the everyday practices of the mission, our empirical research confirmed existing tensions we identified in our policy analysis and interviews with planners in Brussels that constrain its transformative potential. Engagement

\footnotetext{
${ }^{27}$ Radin, 'Analysis of Current Events'.

${ }^{28}$ Radin.
} 
with those involved in the implementation of WPS offered a glimpse of the complex interactions and (f)actors shaping WPS as practice in a deployed mission. In the following sections we discuss three dimensions that complicate our understanding of WPS integration into CSDP practices. These are the context shaping the articulation of gender mainstreaming and the possibilities for its incorporation into everyday practices; the role of gender advisors and gender focal points as key policy "brokers" and, finally, the complex relationships within the mission as an international (and gendered) microcosm.

Reflecting on the gender mainstreaming mechanism: structural constraints and spaces for negotiation

EULEX has one international gender and human rights advisor positioned within the office of the deputy head of mission. The main mechanism for gender mainstreaming works through the establishment of a gender focal points network. Specific gender training has been established for all focal points and there have been some attempts at mainstreaming gender in all the training for staff. In addition, all Human Resources department underwent training in 2015 and a Gender Training for Trainers was carried out in $2016 .{ }^{29}$ Gender focal points are "regular staff" in diverse units within the missions who have been appointed or volunteered to develop own projects with a focus on gender in addition to their regular activities. From a practice perspective studying this mechanism is crucial to explore opportunities for integrating WPS into CSDP everyday practices. That is because training contributes to establish shared knowledge of "how things should be done" and gender focal points can potentially act as "brokers" that translate WPS into the shared repertoire of practices. Our interviews with members of staff variously involved in gender mainstreaming suggests that the creation of this mechanism has been a welcome development. In particular, it could allow for WPS contextual integration into everyday routines in a mission with a diverse mandate and an extensive number of staff active in different roles. However, our interviews also suggest that, in practice, WPS implementation is still shaped by an underlying resistance to see the broader linkages between gender, peace and security as essential and intrinsic to peacekeeping and post-conflict transition.

Notwithstanding that a gender mechanism is in place and that WPS policy commitments figure in the mission's operational documents ${ }^{30}$, our interviews indicate that the incorporation of WPS into the work of EULEX is shaped by the constrained nature of CSDP

\footnotetext{
${ }^{29}$ Email communication with EULEX gender advisor, 25 January 2017

${ }^{30}$ By WPS policy commitments here we refer specifically to the policy documents outlining EU commitment to implement WPS in its external action and CSDP mission, as discussed on pg.6-7.
} 
as a security tool with a very specific and time-bound mandate, rather than a broader approach that seeks to transform conflict and envisions peace. In this constrained context addressing the linkages between gender, peace and security is still not perceived as a priority in the practice of CSDP. For instance, one interviewee provides a sharp assessment of the mission's mandate:

When you look at the OPLAN and its end state: it's very weak. It's very poorly articulated the idea of where we are going and what we want to achieve. In this context is very difficult to articulate the nexus gender, peace and security. We don't have a vision of what peace actually means in a context such as Kosovo. We don't use that language we use a very securitised language, a very vague language of multi-ethnicity, of institutions free from interference, which is very narrow in that sense...so we are not looking at what sort of justice exist ..so we are not having a conversation about how gender considerations should be incorporated into the judicial institutions. we don't talk about access to justice for instance" 31

Echoing our engagement with the CSDP gender specialists we interviewed in Brussels, our research suggests that the reluctance to see gender at the core of EU peacekeeping and crisis management is not simply a matter of imperfect implementation. Rather this goes to the heart of deep-rooted understandings of security and crisis management as gender neutral. A cursory glance at EULEX press releases and media presence offers an indication of the tendency to see gender issues as secondary. It is indeed telling that while initiatives with a focus on gender are featured in the mission's official website, official press releases on the extension of EULEX current mandate contain no references to gender and focus exclusively on the key priorities in assisting the rule of law, i.e. police, judiciary, customs area. ${ }^{32}$ This is echoed in our interviews with CSDP planners who, while vaguely acknowledging the aims of WPS, are still reluctant to see gender as a priority at the higher-level of decision-making and in the practice of CSDP. As a planner we interviewed in Brussels put it: "It [gender mainstreaming] is not a priority. Our priority is to achieve the objectives we have, and member states have set out. Gender mainstreaming can help but when push comes to shove it will fall off the table" 33

\footnotetext{
${ }^{31}$ Confidential interview, EULEX, Prishtina, 22 July 2016

32 'EULEX New Mandate - EULEX Press Releases - EULEX, Kosovo, European Union Rule of Law Mission in Kosovo, EU, European Union, European Union External Action', accessed 30 June 2017, http://www.eulexkosovo.eu/?page=2,10,437. See also EULEX Press Releases, accessed 30 June 2017 http://www.eulexkosovo.eu/?page $=2,10 \& y d a t e=2016$, accessed 30 June 2017

${ }^{33}$ Confidential interview, CPCC, Brussels 24 June 2016
} 
During interviews, gender specialists often question the existence of a broad institutional commitment in the CSDP structures in Brussels to see the WPS agenda as intrinsic to EU crisis management and peacekeeping. This brings us to the key challenges in effectively translating WPS into practice as identified by our research participants. A point which emerged quite strongly in all our interviews is that while gender advisors and gender focal points can attempt to operationalise WPS with interventions at the micro level, the required change in the shared values and background knowledge underpinning CSDP practices must be triggered at higher levels, including relevant institutions in Brussels such as CMPD and CPCC:

"So policies are made by policy makers and it should be those highest in the hierarchy that are responsible for implementation. I think one of the key obstacles and challenges is that there is still not enough awareness and commitment from the top and when that happens we can see many things happening. Also in terms of improving gender balance of the missions, women in decision making and having this institutional shift happening maybe that needs to come from the top."34

A gender focal point shares a similar view by pointing to the importance of shared "standards, values and practices" in legitimating WPS within the professional background and knowledge that constitutes CSDP as practice:

"We need synergic efforts but the driver has to be senior level management. They set the standards values and practices. They have to set a good example. And they have to show it, not only by words but also how they compose their team and select their staff, how they make the organisation, if they are in operation how they decide to give the responsibility, how they give power etc." 35

Other interviewees also point to broader dynamics that go beyond the context of EULEX but rather shape CSDP practices at its core. For example, even though there have been attempts to include gender in all of the EULEX training, a participant suggests, more should be done in terms of mainstreaming gender into the operation and programming of CSDP missions. For this interviewee shortcomings in fully incorporating gender training as key dimensions of peacekeepers skill-set ,however, are symptoms of a larger problem intrinsic to the nature, vision and objectives of CSDP missions at large:

\footnotetext{
${ }^{34}$ Personal interview with EULEX gender advisor, 21 July 2016 Prishtina

${ }^{35}$ Confidential interview, EULEX, 9 November 2016, Prishtina
} 
I have never received any training. The mission has a very close end mandate. But if you have faith in CSDP missions you would think that creating a pool of people ready to be deployed from one mission to another, and therefore some professional training should be important. It is not, particularly in terms of knowledge and skills development. I have attended an anti-ambush training that's it. Gender mainstreaming is part of the induction, which is two days of huge amounts of information so it has its limits. One hour-long presentation can give you an introduction about the concepts but it doesn't explain how do they play out in the mission's activities. ${ }^{36}$

Our research suggests that insufficient attention to professional development and to gender mainstreaming as an important dimension of peacekeeping and crisis management is symptomatic of the transitionary nature of peacekeeping missions inasmuch as from a certain disagreement as to whether training responsibilities lie with Member States and contributing countries, or CSDP structures. For instance, this argument emerged clearly in our interviews with CSDP mission planners based in Brussels. The idea put forward is that developing a pool of practitioners to be deployed should be the responsibility of Member States. We suggest that this tension highlight intersecting constraints shaping the integration of WPS into CSDP practices. . On one level, the disagreement over Member States' responsibility for deployment and training reflects tensions intrinsic to CSDP, as a relatively new policy still fraught between intergovernmental decision-making and the supranational reach of EU soft power into the terrain of foreign policy. ${ }^{37}$ At the same time our impressions from the field indicate that the deferral of responsibility over gender mainstreaming also works as an alibi for lack of accountability, slow progress and generally an unfulfilled commitment to see WPS as central to peacekeeping and security practices. The perceived gap in gender training and professional development of peacekeepers indicates a problem that cannot simply be addressed at the deployment level. Rather it illustrates that the organisational change and shift in security practices that WPS objectives require is shaped by multi-level constraints in the structures of EEAS, the security policy of Member States, as well as in the context of CSDP missions.

We found that a degree of inconsistency exists between the broader commitments expressed in EU policy documents, that as we have shown are already problematic from a feminist perspective, and the progressive narrowing down of gender mainstreaming to fit

\footnotetext{
${ }^{36}$ Confidential interview, EULEX, Prishtina, 22 July 2016

${ }^{37}$ Guerrina and Wright, 'Gendering Normative Power Europe'.
} 
within the remit of CSDP strategic missions. As one of our participants suggests, from an operational point of view this is perhaps inevitable as peacekeeping missions are bound by a very specific mandate. Yet this also suggests that more conceptual and empirical work might be required to better articulate the localised applicability of WPS to CSDP practices in various post-conflict and transitional scenarios:

"All of the main concepts within WPS are important for us: protection, prevention, participation and gender mainstreaming. Of course, we are now a civilian mission in a post conflict setting. It's a very different context from conflict situations and sometimes I have the feeling that for instance protection measures, as they are formulated in WPS policy documents, are more relevant in the phase of ongoing conflict. In some regards, there is less guidance for us as a mission in this context where the focus now is on state-building and establishing the rule of law. Of course, in this context you still have to deal with things that happened during the war, for example sexual violence related to the conflict is an area that has not been properly targeted yet and that's where WPS comes in place" 38

As in our interviews with CSDP gender advisors, the gap between broad and rather general WPS policy statements and the everyday activities of a mission is often mentioned as a key challenge in the translation of WPS into practice. At the same time, however, this gap also creates openings for gender advisors, and to a lesser extent gender focal points, to act as key policy "brokers" and negotiators in ways that could alter everyday practices through contextual implementation and formal and informal interaction. We see their role in the translation of WPS commitments as an important dimension of security and crisis management practices. Drawing on professional dispositions and exercising specific choices these actors and interactions complicate deterministic models for implementation that rely exclusively on indicators, goals and examples of best practices.

\section{Populating the field of WPS practice: Gender advisors and gender focal points as} key agents.

We believe that paying closer attention to how gender advisors and gender focal points operate in specific CSDP contexts, how they perform and reflect on certain tasks and interact with other practitioners, is valuable to gain a deeper understanding of WPS potential to influence CSDP practices. For instance, our research at EULEX suggests that both the

\footnotetext{
${ }^{38}$ Personal interview with EULEX gender advisor, 21 July 2016 Prishtina
} 
positioning of the gender advisor within the mission, as well as their professional disposition are critical to better understand the micropolitics of implementation, as well as its limits. In relation to the mission's structure, we found that the positioning of the gender advisor close to the EULEX chain of command is crucial as it grants access to (some) senior management procedures and opportunities to build a shared repertoire of WPS practices. For instance, part of the gender advisor's work includes providing strategic advice to different lines of operations in the headquarters, attending (a number of) management meetings where gender expertise and advice might be requested, particularly in the creation of the Mission Implementation Plans where the programme of mission's activities is set out. Further to this, the gender advisor is responsible for supporting and facilitating the translation of gender mainstreaming into the practice of the mission through the coordination of the gender focal points system, the development of joint activities and working individually to give advice and coach gender focal points in their work. In this respect, most interviews with EULEX staff suggest that the gender advisor was instrumental in getting people on board, contributing to build the network and offering specialist advice to focal points in order to develop their own "gender" projects. ${ }^{39}$ The Gender Advisor thus, can potentially affect CSDP practices through their professional disposition as WPS experts, as well as through formal and informal socialisation strategies involved in building the network of gender focal points.

In the case of EULEX the international gender advisor has a long-standing experience working in the context of women, peace and security and thus was also open to reflect critically on the process of implementation. Our interview and further personal communications offered great critical insight on the mission's approach to WPS, as well as on the conditions that make certain repertoires of WPS practices possible, while constraining others . The following excerpt is illustrative:

"There is no proper analysis, with regards to gender, made when the mandate has been revised. Of course, in the OPLAN there is a problem analysis, but there is no gender analysis or human rights analysis of the area of intervention. At the same time, there is clear guidance, with quite a strong language, incorporated in the OPLAN about the importance of gender mainstreaming and adhering to all international standards. And this is good, it's important and we can use it. But it's also a sign that it is still not properly understood what it needs to be done to fully

\footnotetext{
${ }^{39}$ This of course also raises concerns about the sustainability of gender mainstreaming, that is as to whether having one gender advisor per mission offers adequate resourcing.
} 
bring gender mainstreaming into the planning process because then it would be shown throughout, and then we would not always have the problem that, when we actually want to implement something, we have to convince everyone that this is in the mandate ...because we always have this reply back: "but this is not in the mandate". 40

Drawing on a specialist knowledge of WPS, these reflections illustrate internal constraints shaping implementation which would not otherwise be accessible to us as researchers given the lack of access to missions' documents and to the everyday practices in the mission. By offering a glimpse into the internal planning and operational context of the mission, these insights suggest that commitment to the broader, transformative scope of WPS still lags and that misconceptions about its relevance to security and peacekeeping practices are deep-rooted among high-level security decision-making. Thus, while a formal acknowledgement of the necessity to mainstream gender and adhere to international standards can offer an entry point to introduce gender concerns and circumvent arguments about WPS' irrelevance to the everyday operation of the mission, a wider transformation of CSDP practices requires the unreserved inclusion of WPS within the "anchoring practices" that form a common CSDP ethos. ${ }^{41}$ Our interview suggests that in the absence of a broader institutional commitment to transform established CSDP values and practices, gender advisors attempt to find opportunities to introduce gender concerns into existing routines, even though this might come at the prices of muting WPS transformative ethos: .

"While that is not happening, it can sometimes be easier to come, like, from the side as we gender advisors always do with certain specific issues. For example, Gender Based Violence which is somehow already understood by everyone that is an area that we have to tackle. So it can be the easy way to focus on that. But I think that the real shift needs to come from the top. We need to work from different levels. We, gender advisors and gender focal points, can work bottom up to integrate a gender perspective, which is not only on GBV[...] But we can never reach all these things from the bottom, there has to be also some movement coming from the management level. The structural challenges because of gender imbalance in all of the institutions and organisations and especially in this male-dominated environment can only change when that shift happens. ${ }^{42}$

\footnotetext{
${ }^{40}$ Personal interview with EULEX gender advisor, 21 July 2016 Prishtina

${ }^{41}$ Nina Graeger, 'European Security as Practice: EU-NATO Communities of Practice in the Making?', European Security 25, no. 4 (2016): 478-501.

42 Personal interview with EULEX gender advisor, 21 July 2016 Prishtina
} 
It is unsurprising that CSDP practitioners' support for WPS often revolves around "established" concepts such as gender-based violence. As we argued elsewhere, one reason why GBV gains traction in CSDP operations might be related to the fact that this is often framed as a problem relevant nearly exclusively to the host society. ${ }^{43}$ In other words, it seems easier to gain support for WPS when gender mainstreaming policies are framed outwardly, that is, they do not call into question personal and institutional complicity of CSDP personnel in reproducing gendered power relations. This approach resonates with another process we noted in our research with CSDP gender advisors, whereby negotiating opportunities to implement WPS often involves translating its objectives in ways that speak to the practicalities of security practitioners, at the expenses of WPS more radical and transformative aspirations. ${ }^{44}$ Our engagement with CSDP gender specialists suggests that, given the generalised resistance to see gender concerns as relevant to security and crisis management , this tension is at the hearth of WPS implementation. This is where perhaps identifying opportunities for multi-level strategic partnerships across the EEAS, member states and EU supranational institution as invoked by feminist institutionalist scholars might be useful in moving the agenda forward by fostering a broader institutional commitment to WPS and gender mainstreaming. ${ }^{45}$

Given its diffusion as a key mechanism for gender mainstreaming, we believe that paying closer attention to the dynamics leading to the creation of the gender focal points system, their composition and professional dispositions adds an additional layer to our understanding of the process and actors involved in translating WPS into CSDP practice. In the context of EULEX, the system of gender focal points (GFPs) is in place since 2015 and, at the time of our fieldwork, between 20-25 gender focal points had been active. All focal points are trained on gender perspective, gender analysis and gender mainstreaming. In EULEX focal points are positioned in different areas of the mission, such as in the training unit, the judge's unit, in the police and correctional services to name but a few. They work both internally and externally and can incorporate a gender dimension to their "daily" work through the development of specific projects. Examples of gender mainstreaming projects are as diverse as a gender sensitive training for judges dealing with gender-based violence cases, the collection of disaggregated data on cases of domestic violence dealt with by the mission ${ }^{46}$, the development and

\footnotetext{
${ }^{43}$ Deiana and McDonagh, op.cit., 8.

${ }^{44}$ Deiana and McDonagh, 12.

${ }^{45}$ Guerrina and Wright, op.cit..

46 These cases are dealt with by Kosovo police and reported to EULEX. EULEX keeps track on these cases and has the possibility to follow up with the KP in case deemed necessary, for example if there are doubts that a case is properly dealt with. Personal email conversation with EULEX gender advisor, 25 January 2017
} 
incorporation of a gender dimension to ongoing and induction training, a survey of women's employment conditions in the correctional service and a proposal for activities that encourage women's participation in the security sector, as well as well as the training of trainers. ${ }^{47}$

The deployment of a project approach aims to make the GFPs work more tangible as opposed to creating a contact point role responsible for mainstreaming gender in all aspects of a specific unit. Given the mission's diverse mandate and the lack of specific guidelines in EU policy documents, the establishment of the GFPs network and the project approach is envisioned as an exploratory strategy to translate gender mainstreaming into everyday practice. ${ }^{48}$ As mentioned earlier, interviewees often highlight the lack of specific guidance as a key challenge they face in WPS implementation, yet this gap also opens interesting opportunities to observe how gender focal points make sense of WPS in relation to their activities, develop concrete strategies for implementation, negotiate their daily routines and enact their discretion.

While providing a full assessment of the GFPs system goes beyond the remit of our project, our fieldwork research offers some interesting, albeit preliminary, insights into GFPs perspectives as new CSDP actors in the field of Women, Peace and Security. For instance, we began our fieldwork with the assumption that focal points share a common understanding of women, peace and security and gender mainstreaming. Interviews and informal conversations, however, produce a much more ambivalent picture: some participants talked about gender mainstreaming in relation to training and professional development opportunities, some interviewees refer to experiences of sexism and inequality within the mission, while other participants tended to speak about gender mainstreaming activities mostly in relation to offering support to the host society. We also took for granted that all participants were familiar with the key objectives of women, peace and security. And yet, the transformative aspirations and themes that we associate with WPS rarely emerge in our conversations with gender focal points.

Similarly, conversations and interviews with GFPs indicate that personal decisions, professional dispositions and interpretations greatly matter for their involvement in the implementation of WPS, as they contribute to shape how ideas of gender, gender equality, and/or gender mainstreaming are continuously translated, operationalised, interpreted and put

\footnotetext{
${ }^{47}$ The Gender TOT was developed in order to try to include a gender perspective into the mission's different training concepts. Personal email communication with EULEX gender advisor, 25 January 2017

${ }^{48}$ Personal email communication with EULEX international gender advisor, 25 January 2017
} 
in practice. Interestingly our conversations reveal why some peacekeeping staff might get involved in WPS, for what purposes and in ways that may not necessarily fit neatly with WPS dominant narratives and larger objectives. In our experience, these ranged from an ideological commitment to gender equality to personal interest, from resentment at the lack of professional recognition to attempts at boosting employment opportunities. While our research confirms the crucial role of gender advisors in constantly translating the agenda, negotiating for spaces of intervention and crafting formal and informal partnerships, it also suggests that those doing gender work inevitably bring their own interpretations of WPS, gender equality, and/or feminism(s) to bear on peacekeeping and security practices. This is not to call into question our participants' knowledge of WPS, rather it is to highlight that a deeper interrogation of what meaning(s) mainstreaming gender assumes from the perspectives of those involved in the field would enrich our contextual understanding of WPS as practice and equip us with richer empirical knowledge about implementation, and its challenges. As noted elsewhere, our research suggests that when it comes to implementing WPS, the political is deeply personal.

\section{The Mission as a Complex Microcosm: International and Gendered}

Interviews we conducted with CSDP mission planners in Brussels resonate with the insidious workings of what Annika Kronsell describes as the EU CSDP masculinities, i.e. European, progressive, outward -looking and civil-minded. ${ }^{49}$ They tended to view gender concerns as something that is relevant for variously defined "others", be it women, females, or other male colleagues who they described as "old-fashioned" or less progressive. They often tended to associate questions of gender inequality with spaces other than EUrope, such as Kosovo for instance, and crucially with spaces such as Afghanistan, always mentioned as the ultimate example of gender inequality. By contrast, they were eager to present themselves as liberal, progressive and "not discriminators", even though a closer look at their statements and views reveals a tendency to dismiss the importance of gender in the context of security or misinterpret gender mainstreaming as an instrument that favours women. There are parallels here with Katharine Wright's findings on NATO and the instrumentalisation of the WPS agenda to an organisation's broader goals and normative signalling involved in being seen to priorities gender issues. 50

\footnotetext{
${ }^{49}$ Annica Kronsell, 'The Power of EU Masculinities: A Feminist Contribution to European Integration Theory', JCMS: Journal of Common Market Studies 54, no. 1 (1 January 2016): 104-20, https://doi.org/10.1111/jcms.12328.

${ }^{50}$ Wright 'NATO Adoption of UNSCR 1325'
} 
Interestingly this generalised resistance to perceive one-self as "a discriminator", as part of the problem of gender inequality emerged vividly also in our interviews with EULEX personnel. The following statement from a gender focal point is poignant:

"For me one of the main challenges [is that] there was a certain resistance from the participants on this subject. People coming for European countries would think "We don't have this problem, why do we need to learn about gender? About human rights?" This was a big challenge especially at the beginning. Of course, we had experts but it was a challenge. I didn't think I was going to find resistance to these issues in a European mission. People are also thinking "We have lots of problems now: terrorism, refugees etc., why do we need to deal with the gender issue?" "There are some individuals (whose attitude is) in "my country everything is perfect I don't need to know [...] Even in our days, people are not so much convinced in equality." 51

Other research participants recounted episodes in which fellow EU peacekeeping staff displayed resistance and hostility to gender mainstreaming initiatives directed internally to the mission. As one interviewee points out, the underlying logic at work is "you don't come here to learn but to teach various "others", in this case the Kosovo local counterparts. Similar gendered constructs are also evoked in the EULEX mandate which, tellingly, relies on the principle of "Monitoring, Mentoring and Advising" as its key articulating strategy. As we argued, these hierarchical constructions of EU peacekeeping masculinities are evoked in the orientation of gender mainstreaming policies, and specifically in the context of gender based violence. This echoes key EU policy documents wherein EU CSDP identity emerges through the notion of EU benevolent, civilizing masculinities responsible for the protection of vulnerable femininities (in the host societies). ${ }^{52}$

Some interviews with those deployed in field further complicate the picture by drawing attention to CSDP missions as shaped by local/international dynamics, multiple cultures (and perhaps stereotypes about specific cultures) and gendered relations. The following excerpts are illustrative of the multiple relations and positionalities in the mission:

"Within EULEX where you have such different cultures and different backgrounds, it is interesting to see coming from (a different national context). In

\footnotetext{
${ }^{51}$ Confidential interview, EUULEX, Pristhina 9 November 2016

52 Kronsell, 'The Power of EU Masculinities'.
} 
my work there I didn't see any difference being a woman. Even working in maledominated environments I was encouraged and supported in taking up new roles etc., but here it is noticeable how you are treated. I would hate to generalise but I have experienced being treated differently because I am female. It was uncomfortable. I discussed these matters with other female colleagues and it is interesting because some practices are not seen as unprofessional, not a violation of privacy. This depends on different backgrounds of the staff who come in a pool of different ethnicities and it is a challenge" 53

"Working with "Scandis", Brits and Germans was easy as we had a commonality of ideas. Coming back now it's different: western Europeans have gone as their countries are no longer contributing. There is a lot of eastern Europeans here now: Hungarians, Bulgarian, Czechs. It's a different place. They have different traditions legally, different attitudes, their understanding to human rights, and different understanding of gender issues. They behave in a very different way, they tend to be more autocratic. Scandis are all very flat. They tend to be very conscious of status and to have traditional views of females and degrees of informality in the workplace, sometimes the western European are very uncomfortable." 54

"I don't want to sound like I'm superior but they are different, they have different ideas .And we are trying to be cohesive so that we can then portray that outwards but we are not ..Strangely though they don't seem to have a problem with women doing well. I think it is more about an informality and how they treat subordinates that you wouldn't get in western Europe." 55

These statements are both revealing and interesting. On the one hand, they are important testimonies of lived experiences of women working in a male dominated CSDP mission. On the other hand, these narratives also reproduce a specific geopolitical and gendered imaginary underpinning the practice of EU security. They do so by reproducing a certain geopolitics of peacekeeping ${ }^{56}$ that revolves around nested hierarchies of Western Europe/Eastern Europe/as "the international" and implicitly evokes Kosovo/the Balkans/the local. They mobilise

\footnotetext{
${ }^{53}$ Confidential interview, EULEX Prishtina, 22 July 2016

${ }^{54}$ Confidential interview, EULEX, Prishtina, 11 November 2016

${ }^{55}$ Confidential interview, EULEX, Prishtina, 11 November 2016

${ }^{56}$ Roland Paris, 'The Geopolitics of Peace Operations: A Research Agenda', International Peacekeeping 21, no.

4 (8 August 2014): 501-8, https://doi.org/10.1080/13533312.2014.946743.
} 
specific attendant gender narratives associated with these hierarchies. For example, the extracts above display the trope of western Europe (Scandis, Brits) viewed as a progressive society and implicitly inhabited by progressive men,. Eastern Europe emerges as liminal space in EUrope - still dealing with $2^{\text {nd }}$ world problems such as faith in hierarchy or different understandings of human rights - and thus implicitly inhabited by unprofessional men. This narrative implicitly evokes the notion of the local context, the Balkans, often presented as a traditional society inhabited by local counterparts in need of training, monitoring, etc. Interesting in these narratives is how the construction of "good" progressive western European CSDP colleagues stands in contrast with the statements and views expressed by western European CSDP male participants whom we interviewed, or their dismissive attitudes towards being the "targets" of gender mainstreaming described by other research participants. In a way, these narratives further complicate Kronsell's notion of EU CSDP masculinities and gesture towards more complex gender and geopolitical hierarchies at play. This puzzling account also suggests that if we are to understand the (f)actors shaping the integration WPS into EU security and crisis management practice we must dig deeper into EU CSDP missions as international microcosms that reproduce complex gender regimes and reflect global disparities.

\section{Conclusions}

This paper aims to contribute to existing research on the implementation of the Women, Peace and Security Agenda into EU CDSP missions by spotlighting the perspectives of the actors engaging in WPS as practice. While we acknowledge existing studies that aim to further develop accountability mechanisms, indicators and strategies for organisational change, these often rely on the assumption that a determined meaning attached to WPS and gender mainstreaming exists, that all actors share that meaning and that will act accordingly to pursue predetermined goals. This paper contends that drawing upon a practice-based approach we can capture the complex, ambivalent and often tortuous translation of WPS into CSDP security and crisis management practices. Interviews with EULEX staff offer an insight into the (f)actors shaping WPS implementation in ways that populate the account of gender mainstreaming with multiple interpretations and interactions. This contextual and empirically driven research adds interesting layers to our understanding of WPS travelling into the terrain of EU CSDP.

Our research confirmed the trajectories and tensions we identified in our policy analysis and interviews with planners in Brussels. Namely, that a reluctance to see gender as crucial to the practice of crisis management and security undercuts the realisation of WPS commitments. 
While the development of a gender mainstreaming mechanism and the creation of a gender focal point network are an important development that might lead to a more diffused implementation in the mission, our research participants highlight the need for a stronger institutional commitment to acknowledge WPS in the shared repertoire of CSDP values and practices. Gender specialists we interviewed contend that not only should there be a more proactive engagement with the agenda in the management structures of a deployed mission like EULEX, but a deeper commitment to WPS' centrality for CSDP should come from high-level decision making in Brussels. This is crucial if we are to achieve the organisational and practical shift that WPS requires in terms of addressing gender inequalities in deployed mission but also more broadly in the framing of security and crisis management practices.

Another key issue emerging form our fieldwork is the reluctance of non-specialist CSDP personnel to engage reflexively with WPS when it extends to address gendered dynamics within their own organisations and practice. Interviews confirmed that the orientation of gender mainstreaming in EU deployed missions is predominantly perceived to focus on local counterparts, in ways that uphold and sustain a self-representation of "progressive" EU peacekeeping masculinities vs. less progressive "non-EU Others". This tendency essentially works to leave masculine culture, complicity and male privilege in CSDP structures intact, and undermines the strategic commitment to take gender seriously in EU security and crisis management practices.

Echoing our conversations with other CSDP gender advisors, EULEX research participants suggest that the gap between the broad commitments set out in EU policy documents on the implementation of WPS and the actual everyday practices of deployed missions constitutes a major challenge in translating policy principles into specific actions. This suggests that more conceptual and empirical work might be required to better articulate WPS applicability to various stages of interventions, including post-conflict and transitional scenarios. At the same time, our research indicates that the gap between policy and everyday practices creates openings for gender advisors, and to an extent gender focal points, to act as key policy "brokers" and negotiators in ways that complicate straightforward understandings of implementation. For this reason, paying attention to the ways in which they intervene in the translation of WPS policy into routinized CSDP practices, and to what effects, becomes even more important to gain a better understanding of the contextual dynamics shaping implementation, as well as its challenges. 
Our interviews and observations with gender advisors and gender focal points at EULEX, as well as our research with other CSDP gender advisors, indicate a heterogeneity of WPS interpretation and professional dispositions that complicate deterministic accounts of implementation exclusively in terms of indicators, goals and examples of best practices. Our research at EULEX reveals that the gender advisor's positioning with the mission, their professional disposition and engagement with WPS matter greatly in translating policy principles, negotiating opportunities for implementation, establishing the network of gender focal points, as well as developing critical reflections on current security practices. The emergence of gender focal points as "new" policy actors also offers interesting insight into the complexity of WPS practices. In this respect, interviews challenged our assumptions about a shared meaning attached to gender mainstreaming and Women, Peace and Security. Rather it became evident that gender focal points draw on different understandings on the meaning and focus of gender mainstreaming policies, which are also shaped by both professional dispositions and personal circumstances. This is not to call into question research participants' knowledge, rather we want to point out that a deeper interrogation of their perspectives, motivations and interpretations would enrich our grasp of WPS potential to reshape current CSDP practices. Interviews also highlighted the complex intersections of gendered order and international imaginaries shaping everyday practices and professional relationships. Paying attention to a mission's professional cultures and subjectivities would enrich our understanding of WPS as emerging from the interaction between policy discourses, institutional cultures and the worldviews and action of CSDP/WPS actors.

Existing studies underline that the value of employing a practice-based approach in the context of security lies in the ability to conduct immersive empirical research in a specific security context. ${ }^{57}$ While we could conduct a good number of in-depth interviews and gain a sense of EULEX institutional culture, we are aware that our interviews only begin to unearth the perspectives of WPS professionals. We thus see our findings as a preliminary intervention into the translation of WPS into CSDP practices . Our project highlights opportunities for a deeper contextual interrogation of how key CSDP actors involved in WPS“conceive their roles, how they go about their daily routines, how they incorporate security practices and perform their identities, how they justify their actions. ${ }^{" 58}$ By offering the view from below, a focus on everyday CSDP practices complements existing approaches that study the institutional and

\footnotetext{
${ }^{57}$ Bigo, 'The (in)Securitization Practices of the Three Universes of EU Border Control'; Côté-Boucher et al., 'Border Security as Practice'.

${ }^{58}$ Côté-Boucher et al., op.cit., 200.
} 
strategic level of WPS implementation. Pursuing this approach could also offer relevant insights for CSDP practitioners.

\section{ACKNOWLEDGEMENTS}

An earlier version of this paper was presented at the workshop on Gender and Security organised by the editors of Global Society at University of Kent. We appreciate the comments received there. We would like to thank the editors and the two anonymous reviewers for productive suggestions and helpful feedback. We thank the Institute for International Conflict Resolution and Reconstruction and the School of Law and Government at DCU for hosting our project. Last but not least, thank you to all the contributors who shared their time and expertise with us and made this project possible.

\section{FUNDING}

This work was supported by the Irish Research Council New Horizons Starter Grant Scheme \#loveirishresearch [REPRO/2015/101].

\section{CONTRIBUTORS}

Maria-Adriana Deiana is an Assistant Professor in International Relations in the School of Law and Government, Dublin City University, Ireland. Her research draws on feminist approaches to war and security. It focuses on gender dynamics of conflict and post-conflict transformation, the Women, Peace and Security (WPS) agenda, EU border politics and peacekeeping.

Kenneth McDonagh is an Associate Professor of International Relations in the School of Law and Government, Dublin City University. His research examines EU security and defence policy with a focus on CSDP missions, gender and the everyday practices of peacebuilding and peacekeeping, and inter-relationship of security and identity narratives from the individual to the global. 